\title{
Textile education during the 2020 pandemic: experiences in US, South Africa and Germany
}

\author{
Christopher M. Pastore, ${ }^{1, *}$, Yordan Kyosev², F. A. Fassihi $^{3}$, Becky Flax ${ }^{1}$ \\ ${ }^{1}$ Kanbar College of Design and Engineering and Commerce, Thomas Jefferson University, Philadelphia, PA, US \\ 2 Institute of Textile Machinery and High Performance Material Technology, TU Dresden, Dresden, Germany \\ ${ }^{3}$ Clothing and Textile Studies, Durban University of Technology, Durban, South Africa \\ * Corresponding author E-mail address: Christopher.Pastore@Jefferson.edu
}

\section{INFO}

CDAPT, ISSN 2701-939X

Peer reviewed article

2021, Vol. 2, No. 1, pp. 18-33

DOI 10.25367/cdatp.2021.2.p18-33

Received: 14 February 2021

Accepted: 24 April 2021

Available online: 24 Mai 2021

\begin{abstract}
The Covid-19 pandemic has had a major impact on higher education across the world. In this paper we consider how textile education has been impacted and what approaches have been employed to maintain quality education and laboratory experience when traditional methods are not appropriate. This paper considers three different countries - United States, South Africa and Germany. Each has been affected in a different way, has a different sociological makeup, and has developed distinct solutions to the challenge. Methods related to HyFlex, flipped classrooms, and blending learning have been applied by all three institutions. Lectures have been presented as pre-recorded videos, synchronous video conferencing, and hybrid. Similarly, laboratory and studio experiences have been handled through pre-recorded video, guided "at home" experiments, and modified in-person experiences. This paper gives an overview of the laboratory and studio experiences, time spent in preparation, and reaction of the students to remedies. It also addresses best practices from each country in the three continents.
\end{abstract}

\section{Keywords}

textile education,

COVID-19 teaching,

concurrent classroom,

hybrid teaching,

remote teaching,

textile studios,

textile laboratories,

student engagement
(C) 2021 The authors. Published by CDAPT.

This is an open access article under the CC BY-NC-ND license https://creativecommons.org/licenses/ peer-review under responsibility of the scientific committee of the CDAPT.

(C) 2021 CDAPT. All rights reserved.

\section{Introduction - limitations to meeting in person}

The COVID pandemic situation created an unusual situation in for textile education across the planet. Textile engineering and design traditionally involve a significant amount practical training, both laboratory and studio, to enrich the theory. The pandemic kept students at home, which meant that practical training (laboratories and studios) had to be re-envisioned. The authors of this paper had intensive exchange during the period. Each country had different requirements and restrictions associated with higher education. The methods employed and evaluations of those methods were collected to create this 
summary of their experience in three different countries - United States (USA), Germany and South Africa (SA).

First, we consider the restrictions applied to each university, considering national, regional, and institutional and applying the more rigorous rules. One of the restrictions associated with the pandemic was physical spacing issues for students and faculty. The formal limitations per country are summarized in Table 1.

Table 1. Comparison of limitations to in-person meeting.

\begin{tabular}{|l|l|l|l|}
\hline Criteria & \multicolumn{1}{|c|}{ USA } & \multicolumn{1}{c|}{ Germany } & \multicolumn{1}{c|}{ SA } \\
\hline $\begin{array}{l}\text { Maximum } \\
\text { Occupancy }\end{array}$ & 25 & $\begin{array}{l}\text { online only, except } \\
\text { exceptional cases }\end{array}$ & 25 \\
\hline $\begin{array}{l}\text { Individual } \\
\text { Spacing }\end{array}$ & 2 meters & 1.5 meter & 2 meters \\
\hline Masks & Mandatory & Mandatory & Mandatory \\
\hline $\begin{array}{l}\text { Students on } \\
\text { campus }\end{array}$ & $\leq 25 \%$ capacity & $\leq 10 \%$ capacity & $\leq 33 \%$ capacity \\
\hline Additional & $\leq 5$ people per $90 \mathrm{~m}^{2}$ & $\leq 5$ people per $100 \mathrm{~m}^{2}$ & $\leq 5$ people per $100 \mathrm{~m}^{2}$ \\
\hline
\end{tabular}

It can be seen that the general criteria shown in Table 1 are quite similar for all three universities. Distinct restrictions associated with each university are explained in detail below.

\subsection{USA}

In the United States, specific limitations on gatherings are determined at the state or city level. Data presented in Table 1 are for Thomas Jefferson University (TJU) in Philadelphia, Pennsylvania. At TJU students who wish to stay at home and learn remotely, may. This means that each class is potentially different regarding attendance. Classes may be entirely online (if all students choose to stay at home), or a combination of in-person and online students.

In the United States, some universities opened the Fall 2020 semester with entirely in-person classes. At several institutions, outbreaks of Covid-19 resulted in them converting to online only in a matter of days or weeks.

University of North Carolina, Chapel Hill identified four coronavirus clusters, and reported that 135 students had been tested positive for Covid-19 in the first week of in-person classes. Thus one week after classes began, the university converted to online only [1]. University of Notre Dame started with inperson classes and converted to all after reporting 304 positive cases since August 3, 2020 (that number climbed to 336 cases by 21 August, 2020 [2]. North Carolina State University converted to online only after 2 weeks of classes [3].

TJU opened in a concurrent mode [4] where students are free to choose if they wish to attend classes in person or stay at home and participate remotely. The faculty teach the classes with video streaming so that in-person and remote students are attending simultaneously. This model is related to the Hyflex model [5] but not as robust, nor as demanding on the faculty.

\subsection{Germany}

In Germany, TU Dresden decided to start the Fall semester completely online. During the second half of the semester, after the situation became controlled, practical trainings were allowed to use an in-person format, if no other form was possible or suitable. This allowed for practical elements to have hybrid forms of learning [6], combining online materials, handouts and partial practical exercises. In the hybrid mode, classes can either meet in-person, or can be online. There is no intention of combining the two modes simultaneously. 


\subsection{SA}

In South Africa, the minister of education has allowed 33\% of students and staff to experience in-person teaching to maintain social distancing [7]. This creates a challenge in determining which students can physically attend the university, and correspondingly, which faculty. DUT has decided to meet this requirement by only allowing final year undergrad and postgraduate students to have access to the campus. The rest will be taught remotely. These $67 \%$ students who are taught online will gradually return to university as conditions improve and level of restrictions eased. Special attention will be made to opening laboratory and practica sessions for these students.

\section{Technical requirements}

Because of the restriction on in-person attendance, some educational components must be delivered remotely, as described above. There are technological needs associated with this requirement, both hardware and software. Of particular interest are the software requirements associated with each of the universities.

\subsection{USA}

Many courses will be using a simultaneous broadcast system because of the concurrent teaching model. In this mode the professor will live stream the class activity using a web camera, microphone, and broadcast software such as Zoom or Blackboard Collaborate. The university provided licenses for Blackboard Collaborate, Zoom and Microsoft Teams to all of the faculty. TJU uses Canvas as a learning management system which becomes the primary repository for digital assets for each course. Blackboard Collaborate (video conferencing software) is available as a built-in tool within Canvas. However, despite the convenience of using Collaborate, almost every faculty member has been using Zoom to run their classes.

All three video conferencing software platforms available to the faculty have the same core functionality - screen sharing, file sharing, and viewing of attendees. Collaborate is limited to showing only 4 participants simultaneously, whereas Zoom allows 49. Most of the faculty felt it important to see the entire class in one screen, so have been using Zoom.

Some classes will involve pre-recorded content that will be viewed by the students at home. These viewings are complimented by live discussions about the content using digital communications, thus creating a flipped component to the course [8]. The development of the pre-recorded content requires access to a quality digital camera as well as video editing software, both of which were provided by the university, an example of which is shown in Figure 1.

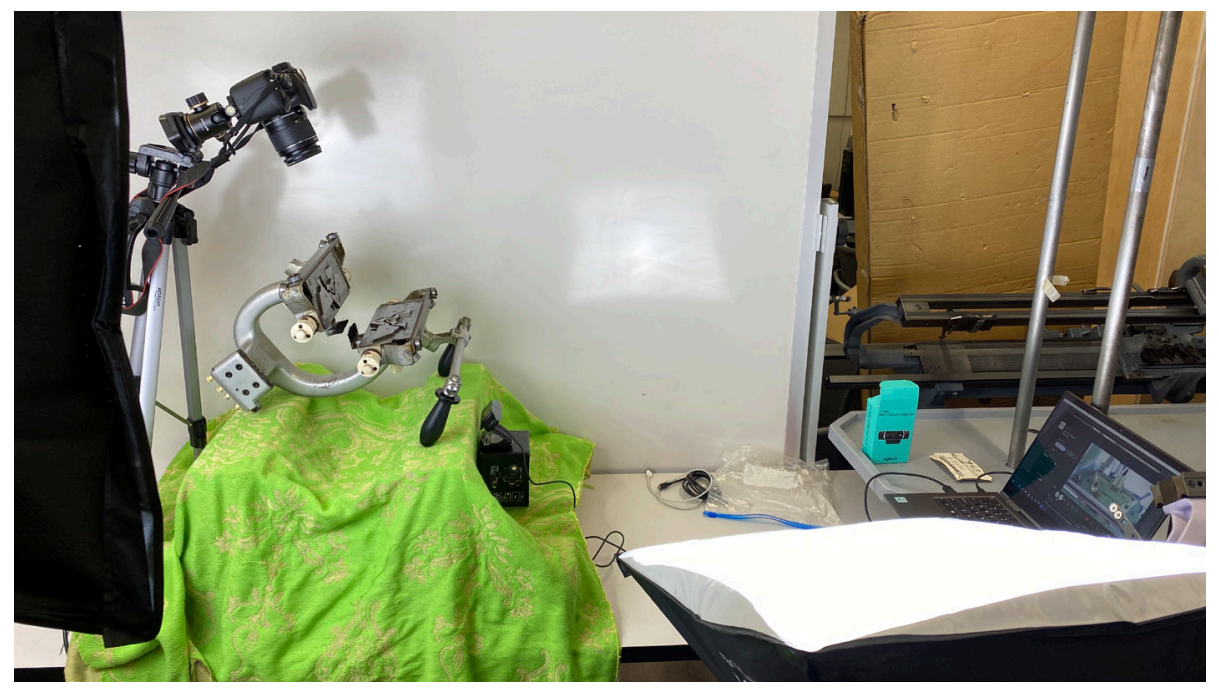

Figure 1. Setup for creating video content regarding the use of flat bed knitting machines. 
Because of the high digital content demands, there were concerns about students having reliable access to the feeds. The vast majority of students had no difficulties, but occasionally a student would run into local internet outages for some period of time. One student reported driving to a McDonald's restaurant to make use of their free internet services to attend class.

\subsection{Germany}

TU Dresden uses the online education system OPAL developed by the state of Saxony [9]. OPAL functions as a learning management system and is available to all members of TU Dresden. Additionally TU Dresden employs the online conference platform of the German universities, DFNconf [10] for online meetings and teaching. The sudden increase in use of video conferencing resulted in significantly increased traffic for DFNconf. To accommodate the need, licenses for various platforms like Zoom and GoToMeeting were obtained for faculty.

Based on the previous experience of one of the authors as well as the possibility for converting existing slides into online content, the author preferred to install separate DokuWiki [11] instances to store the online content associated with the practical training in the assemblage of textile technologies.

No students reported they were not able to access the digital content. There were a few cases reported where the students starting looking at it only in the last two weeks of the semester.

\subsection{SA}

The $67 \%$ of students who are not allowed on campus will be taught using digital tools such as Moodle, Microsoft Teams, WhatsApp, etc. Therefore, a multi-modal approach has been taking place, with classes developed as either hybrid or concurrent.

One of the challenges in SA is that availability of internet access to all students [12]. Very few of the students own a computer, but most have access to a smartphone. To ensure that the students can attend virtual classes, data has been provided by university for all students who are taught remotely. There are some students living in rural areas with no internet access. For these students, printed materials and memory sticks containing lectures and videos were delivered via courier.

\section{Student responsibilities}

In different countries there are different student responsibilities associated with the classroom. The length of the semester, the number of hours per week spent in the classroom, whether or not it is mandatory, and the basis of grading vary. A summary of the attendance responsibilities is shown in Table 2.

Table 2. Comparison of Student Responsibilities in the Three Countries

\begin{tabular}{l|l|l|l|}
\multicolumn{2}{c}{ Germany } & \multicolumn{1}{c}{ South Africa } & United States \\
\hline Semester duration: & 26 Oct -6 Feb & 28 Sept -17 Jan ${ }^{1}$ & 24 Aug -4 Dec \\
\hline Lecture attendance & Optional & Mandatory & Mandatory \\
\hline Laboratory attendance & Mandatory & Mandatory & Mandatory \\
\hline Mid-semester assessment & Rarely & Yes & Yes \\
\hline
\end{tabular}

As can be seen, all three countries have a mandatory laboratory attendance policy, which created a real challenge during this time and required creative solutions.

Also we noted that a mid-semester assessment was a very important part of the experience, as will be described later.

${ }^{1}$ This year the semester is unusual. Typically it will run July to November, but it was delayed because of the pandemic. 


\section{Approach}

It is important to recognize at the outset the difference between online education and remote education $[13,14]$. In online education, students are choosing to enter into an asynchronous teaching experience. This is often because the student is working or otherwise engaged during traditional class time, and so they choose to engage the material at whatever days and times best suit their schedule.

In the case of remote education, the education remains synchronous and students are expected to maintain a specific schedule of attendance. For most of us, the emergency transition was treated in a remote education mode, at least to some degree. Many students preferred having a scheduled class time. In a recent study, Milligan [15] evaluated student preferences for synchronous vs asynchronous remote engagement based on the sudden transition to remote teaching in March of 2020 in the US. He found a distinct preference for synchronous engagement on the part of the students. Further he found that in the organic chemistry classes that were considered, student performance (as measured by exam performance) was higher in the classes with synchronous delivery compared to asynchronous delivery.

The difference between online and remote teaching is the difference between synchronous and asynchronous student engagement.

There are different ways in which the emergency transition was handled. The different techniques employed by the authors are described below.

\subsection{Blended learning}

In all three countries, some classes involved a version of blended learning [16] that was rapidly adapted to the current situation. A typical version of this involved dividing the class into groups, with one group being on campus while the other group(s) experienced online learning. Then on the next class meeting the cohorts changed their modality. For example, a class with 20 students that meets on Tuesdays and Thursdays would be split into two groups of 10 students each. The first group will come to campus on Tuesday and stay at home on Thursday. The second group will stay at home on Tuesday and come to class on Thursday. When on campus, the learning experience will be a traditional version of the classroom experience, but with masks and physical distancing. When possible, the in-person classes met outdoors, as shown in Figure 2. When students are at home, the learning experience will be online.

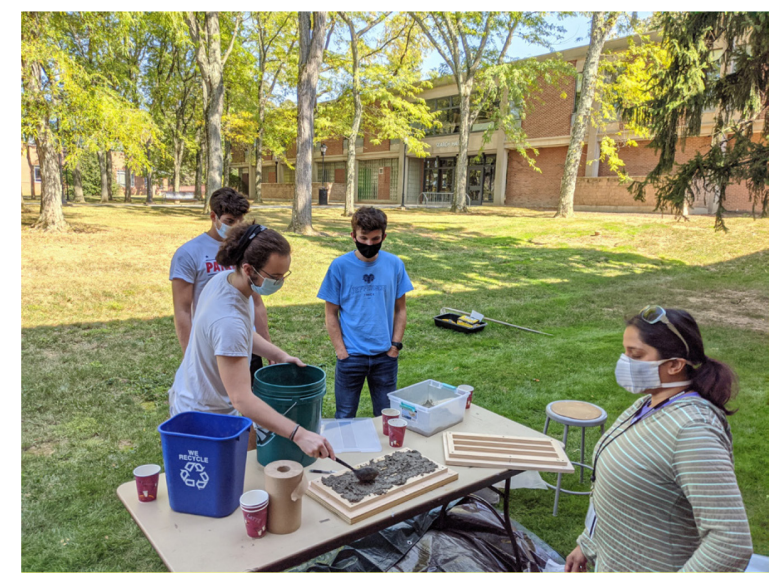

Figure 2. Students performing laboratory outdoors.

\subsection{Hybrid/flexible learning}

Some classes employ a variant of HyFlex (hybrid-flexible) learning [5], although not as robust as implemented in full developed Hyflex classrooms [17]. In these situations, students are free to choose if they can attend the class or not on a daily basis. The faculty prepare asynchronous elements for students who cannot attend a specific in-person class. Thus, students will be synchronous some times 
and asynchronous others, as fits their schedule. The rapid solution that most schools adopted is really concurrent learning, not HyFlex (see below).

\subsection{Concurrent learning}

In the concurrent learning model, the classroom is simultaneously streamed online so that students may attend in-person or from home [18]. Note this is different than HyFlex in that there is no designed asynchronous element for students who cannot attend at the scheduled time. At TJU (US), during the scheduled class time of Engineering Statics, students either joined remotely via Zoom or showed up in the classroom (wearing masks and keeping a 2-meter spacing from each other and the instructor). The live conversations were streamed via Zoom. In these class sessions, the professor has the students solve problems and provides guidance. Sometimes the class works together, other times the class breaks into small groups using breakout rooms in Zoom. The classroom is conducive to this process as it contains a smart board and multiple video monitors throughout the room (Figure 3).

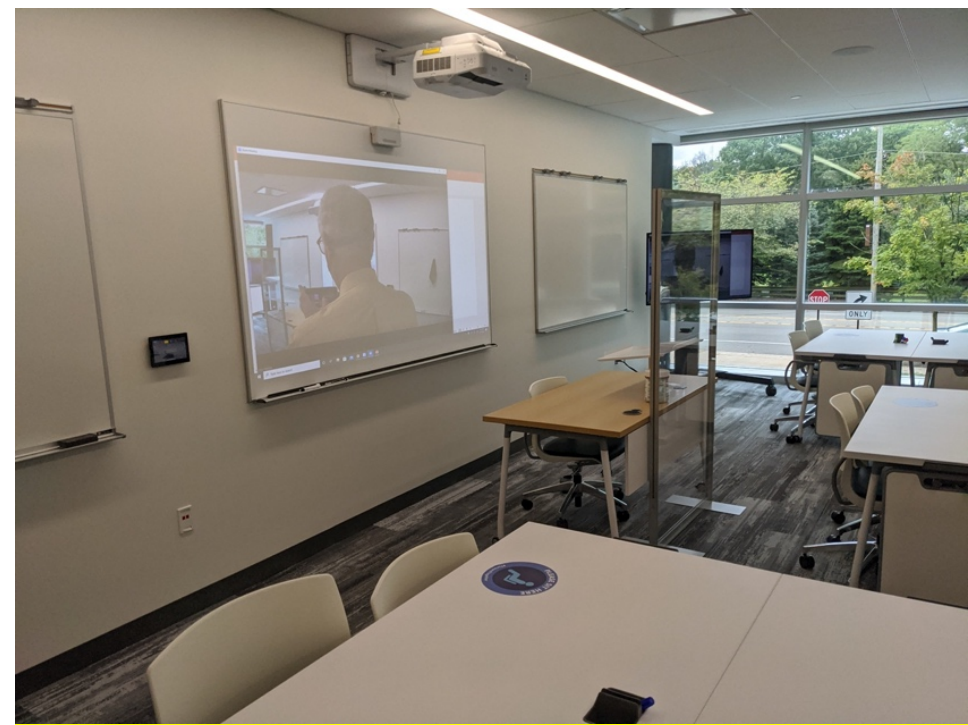

Figure 3. Classroom for Engineering Statics, showing smart board, vinyl barrier and monitor.

\subsection{Flipped classrooms}

A flipped classroom [8,19] has traditional lecture materials provided as online content and the synchronous activities are focused on problem solving and pursuit of activities traditionally associated with homework. Incorporating "productive failure" (wherein the students work on problems prior to receiving instruction on the topic) in the flipped classroom has been shown to increase student achievement of conceptual understanding [20]. In a flipped classroom environment, the instructor may record themselves giving a lecture, and edit that into several small pieces (5-10 minutes each). These videos are provided to the students online through a learning management system. Students are instructed to watch the videos and read assigned documents prior to joining class. There may also be problem sets for the students to engage. During the synchronous class session, students will engage in problem solving, discussions, and other active learning experiences based on their previous viewing, reading, and problem engagement.

At TJU (US), Engineering Statics is a flipped class that employs open educational resources. The professor developed a series of about 100 video lectures that are each about 5-10-minute length. The text book is from the Open Learning Initiative (OLI) at Carnegie Mellon University, which provides a digital course text and tests to the students at no cost. There are multiple online assessments each week. The OLI text book has a series of short questions at the end of each section. The pre-recorded videos have built-in quizzes, where the video stops until the student answers the questions, accomplished using Studio - a video tool within Canvas. There are additional quizzes embedded in 
Canvas that the students must answer before they can see the next video, using the prerequisite function of Canvas. In addition to these low stakes assessments, there are monthly examinations. The students will have over 100 small assessments in addition to 4 major assessments in the course.

\subsection{Online small groups}

A technique employed within a synchronous online class experience is to make use of small online groups, often called "breakout rooms", during the class. In this way the online session is varied between one large room with all students and professor participating and multiple small rooms with only a few students sharing. This can be good for performing class activities such as "think-pair-share" in an online environment [21].

Each of the universities makes use of breakout rooms during streaming classes to allow the students to process new information presented to them during the session.

\section{Specific Examples}

\subsection{Germany}

One of the problems in the teaching of pattern making and 3D clothing simulation remotely is software licenses. Not all software vendors offer student versions of their software and the students cannot remotely access the university computer systems that have site licenses. Grafis (2D patterning software) has a long-term educational version, which the company extended specifically to help students during the pandemic. CLO3D offers a limited 30-day license version for no cost. All of the other providers have licensing fees that make the use of the software possible only in the lab on university owned hardware. The only known freeware for pattern making, Valentina, is not used by Germany companies yet, and also does not provide the full range of features that the commercial packages offer. Because of this, the content delivery had to be re-organized so that the CAD content could be covered within the 30-day license of CLO3D, allowing the students to run the software at home for no cost.

Early in the emergency teaching period, it was discovered that the topics of algorithmic thinking and programming were areas in which the students were not achieving at an acceptable level. To support student success, a separate series of independent lessons with step-by-step demonstration of writing the first lines of code in Python, creating variables and using that for the creation of 3D geometry was prepared and offered to the students. Most of the students worked very actively on these tasks during the semester. These tasks were considered part of the exam. Motivated by this, students submitted their solutions on time. At the end of the course they confirmed that they had learned the necessary skills. The students were happy with the learning software and they enjoyed creating models by doing. A sample of student work on this task is shown in Figure 4.

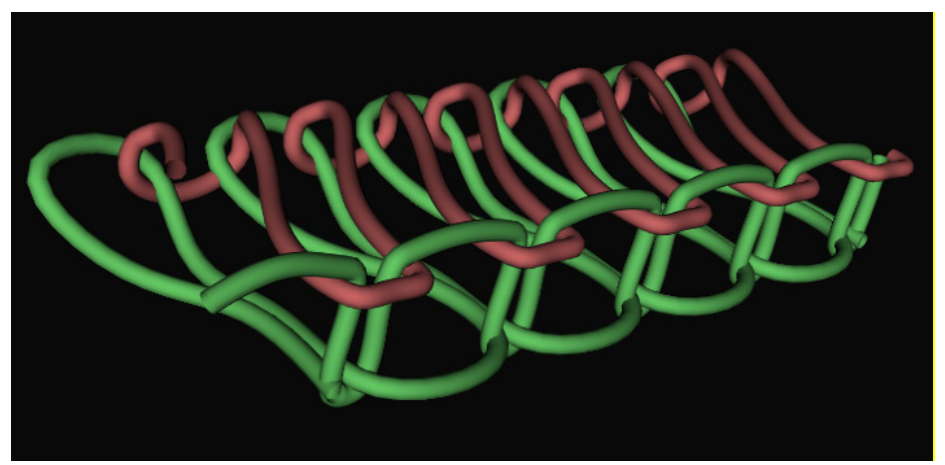

Figure 4. Parametrically generated 3D simulation of 3-thread stitch during the study using Python language and Texmind Viewer. 


\subsection{SA}

Only $33 \%$ of total university student are permitted to be present on campus. The other $67 \%$ must participate remotely. This offered challenges in South Africa as not all students have access to quality internet connections, or can afford a data plan appropriate for remote learning (unlimited data is unusual in SA). To address this, Durban University of Technology provided sufficient data access to all students and some staff for internet connectivity. For students that have no access to the internet, physical copies of materials as well as digital copies on memory sticks were delivered to their homes.

Class schedules were adjusted to account for shutdowns (see Table 1) and new timetables were introduced and communicated to all students and staff.

Moodle is used as the primary communication and course management tool for all classes. Study materials in form of notes, PowerPoint presentations, short video recordings, YouTube clips on processes, etc. were uploaded or linked to Moodle before teaching started for each section.

Students living in remote and rural areas have very poor access to the internet. In addition, not all students have the necessary devices to communicate digitally. About $60-70 \%$ of the students do not have access to a computer of any kind except smart phones. Not all students have a smart phone. The university is in the process of providing devices to those who do not have one. At this point, including phones, about $85 \%$ of students have some level of access to the internet.

Although all classes use Moodle, several faculty also made use of WhatsApp for their courses. The DUT Clothing program uses WhatsApp very effectively. WhatsApp was loaded on staff laptops, and lecturers can (and do) record audio over power point slides or photos during lectures. These videos are shared with the students if they cannot attend synchronously.

Comparing the effectiveness of the two digital platforms, it was found that student participation was higher with WhatsApp than Moodle. Based on second year Textile Technology classes, online class attendance using Moodle was about $30-40 \%$ at best, but on WhatsApp it is about $80-90 \%$, as illustrated in Figure 5.

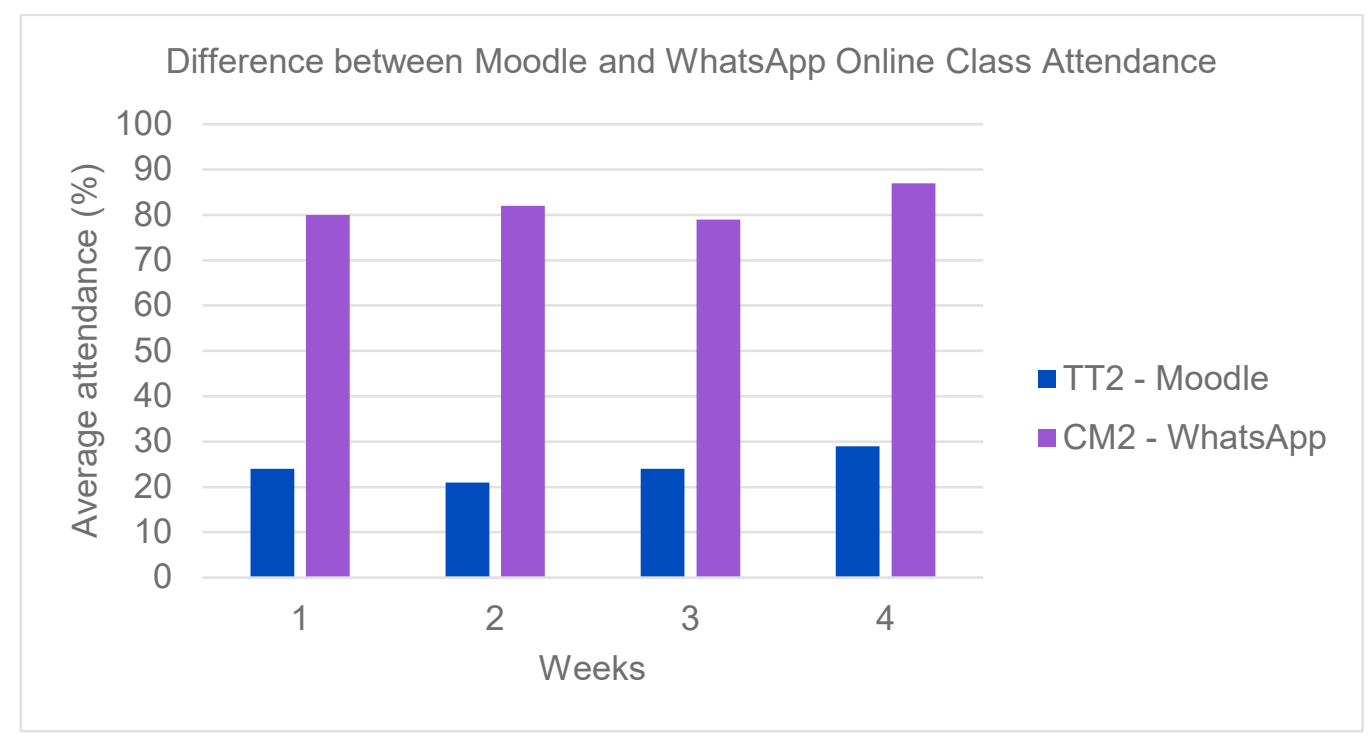

Figure 5. Second year Textile Technology student attendance as a function of distance collaboration tool: Moodle or WhatsApp at Durban University of Technology.

A comparison of first and second year students for classes using WhatsApp showed the participation of second year students was better than that of first year students, as shown in Figure 6. 


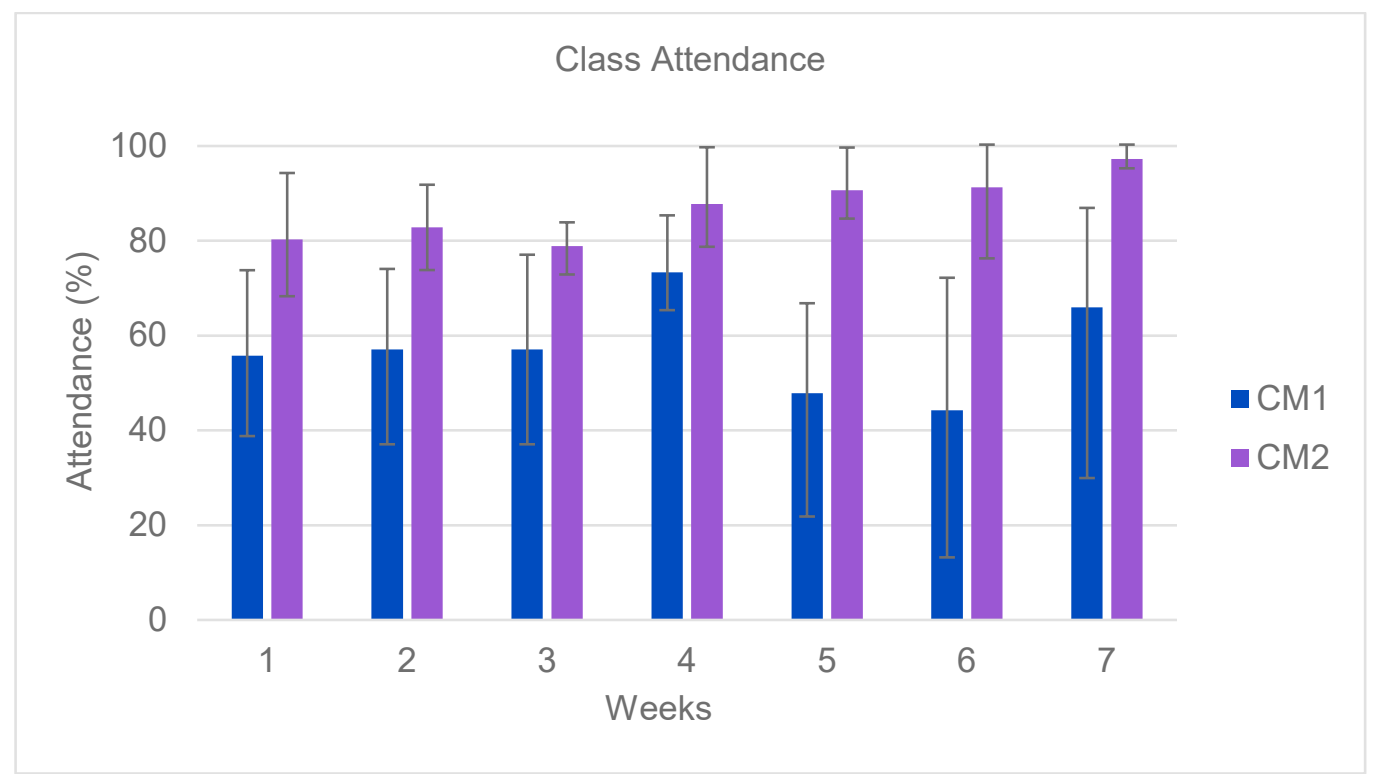

Figure 6. Comparison of Clothing Management 1 and Clothing Management 2 student attendance at DUT.

Because the majority of the students do not have access to a computer, the use of software such as Gerber and CAD as well as hands-on practical experiences were scheduled towards the end of semester when students were allowed to return to campus in smaller groups. The practical experiences were staggered so that when one group was attending laboratory work the other group was attending online classes. These online classes were recorded and uploaded for all groups to maintain safe social distancing.

\subsection{USA}

In preparation for a blended learning experience [22], faculty created demonstration videos using weaving, knitting, and print equipment present in the TJU laboratories and studios. Students were encouraged to view the videos before and during in-person learning experiences. Students view the prerecorded elements and also come to the campus for in-person experiences.

Challenges arise during class time in the event of an error by the student. In traditional times, the faculty would stand beside the student to assist them in resolving the issue. During the pandemic, to maintain safe social distancing, faculty took one of two approaches:

(1) they encourage the student to analyze the situation and talk through how to resolve it, or

(2) switch physical positions with the student and address the complication.

For Computer-Aided Design (CAD) based learning in Jacquard woven, electronic knit, and digital print development, methods were developed to permit students to access terminals on campus that run the specific software via a remote desktop client. In doing this, license permissions remained with the university, and students' access to these resources is equitable. The faculty created several step-by-step procedure screen-recording videos for processes related to the software they teach. The video content is provided to the students via the university's learning management system (Canvas). Students use valuable synchronous digital learning time to ask questions and present design development for critical review.

The companies that produce this software are pushing for advanced simulation development to remove pressure from the strained supply chain. Students learn to analyze the simulation results compared to the textile goods produced on the studio's industry-grade equipment. Analytics generated from these trials allow the students to create more realistic expectations for consumers and prepare them to design more efficiently. 


\section{Assessment}

Assessment of student work is of paramount importance. In this unusual environment, special attention was paid to the methods of assessment to ensure learning was happening. Comparisons between the traditional student performance and achievement in the emergency state was performed.

\subsection{Germany}

Traditionally, the courses are assessed by a final examination coupled with performance in laboratory experiences. However, with the transition to remote learning, it was decided to provide multiple assessments throughout the semester.

For example, in Machines and processes in the clothing industry, several pieces of homework were combined to be considered part of the final exam. The faculty developed 4 individual tasks with defined deadlines. For instance, task 1 was:

- create parametric 3D model of the sewing stiches,

- visualize these models,

- generate different human bodies with available open source software,

- prepare cross sections of the generated body with ParaView,

- calculate the circumference of the sections, and

- simulate the garment on a human body using Blender, while varying the bending, areal density, and shear properties of the fabrics. An example of student work is shown in Figure 7.

In contrast, another course, Construction of sewing and welding machines, used the traditional single final exam with no points awarded from homework during the semester. The participation with the online lessons was "moderate" - approx. $40-50 \%$ of the students were always online following the lectures, but the remaining students only checked the material asynchronously. The results in the exam were also "moderate". For this subject it is difficult to create realistic tasks for doing things at home, because the main phases of the machine motion and the interactions between yarns and machine elements have to be studied. These can be shown with animations and video recorded films, but this is still passive learning, and not experimential.
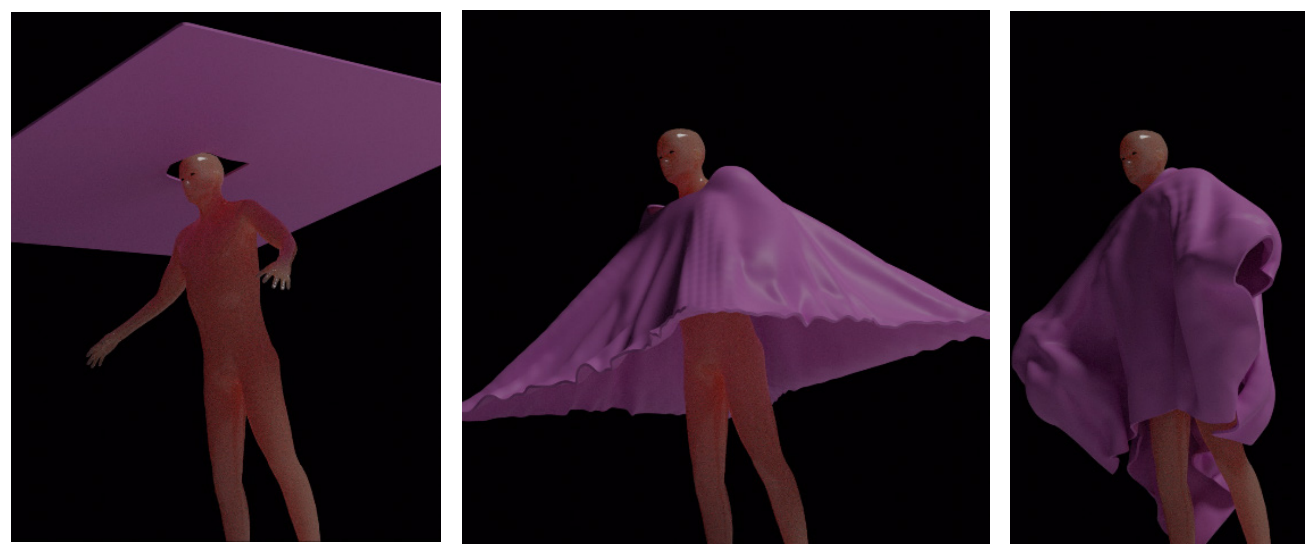

Figure 7. Three steps of simulation of the interaction between human body and cloth with the open source software Blender

\subsection{SA}

Due to the required change in teaching and learning modes from contact to blended learning, all examinable assessment methods for the Textile Science and Textile Technology programs were revised. Traditionally the assessment consisted of in-person course work with a major assessment at the end, but currently has transitioned to continuous assessment, where a number of formative assessments are graded and tallied throughout the semester to determine the final mark. 
In this blended method each faculty member gives a number of graded assignments throughout the semester, with a minimum of 3-4 assessments around weeks $6,9,12$ and 15, as well as additional assessment at the end of the course for borderline students (a make-up assessment). Students are given grades after each mid-semester assessment within a week of submission. The lecturers also provide feedback to the students regarding their performance in the class about their performance so far.

\subsection{USA}

The challenge of evaluating student textile work now encompasses a more extensive range of criteria. Color and texture evaluations relate to salability and market appropriateness. Scale, drape, stitch density, and other performance characteristics define end-use possibilities. Notably, the tactility of student produced textiles informs about success in student development. Removing in-person interaction with textile ideation, creation, and critique means that students and faculty had to communicate and assess those characteristics in novel and innovative ways. Documenting a collection of textiles as more than a grouping of flat surfaces, demonstrating the hand of fabric using video content, and using slide layout, color story, and typography as tools to enhance a collection are now criteria in assessing textile presentations.

The absence of in-person critiques and the ability to evaluate the fabric's qualities in hand has forced the students to research and expand their digital documentation and presentation knowledge. Using cellphone cameras and photo-processing software, students build professional presentations that demonstrate their technical textile understanding and aesthetic abilities. Within one semester, the professional progression of student work is dramatic. In each step, evidence of more significant investment in their process and documentation is clear. With an uncertain future and a rapid transition to virtual interviews, students have adjusted rapidly to exhibiting and communicating the successes of their developments and their textiles' physical attributes.

\section{Student Response}

\subsection{US}

The forced remote instruction empowered the students to think critically about their process and issues that arose. Students were responsible for continuing to develop their creative practice with whatever resources they had at their disposal. In the Spring 2020 semester, one student created a circular knitting device from a hair curler and flat metal bobby pins to achieve the required tubular knit structure, as shown in Figure 8. Another student created dress forms from household items, including a makeup brush and pool noodle, to construct and display her capstone collection.

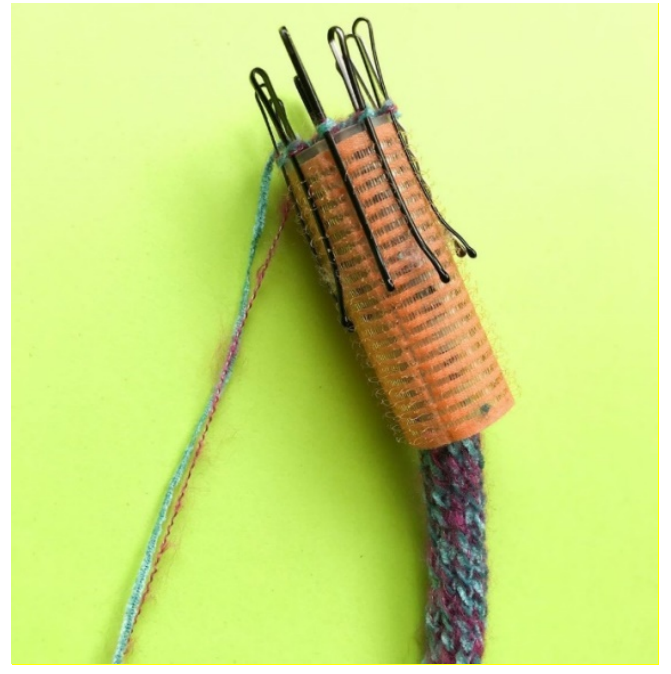

Figure 8. Circular knitting device created at home by one of the textile students. 
Students were asked to complete a voluntary survey about their experience with the classes this semester. They were asked to rate different elements of the course on a scale from 1 (very not-useful) to 5 (very useful), including overall course progress, as well as synchronous lecture, pre-class readings, quizzes, discussion boards and pre-recorded videos. For one lecture-based engineering class, the students' responses are shown in Figure 9.

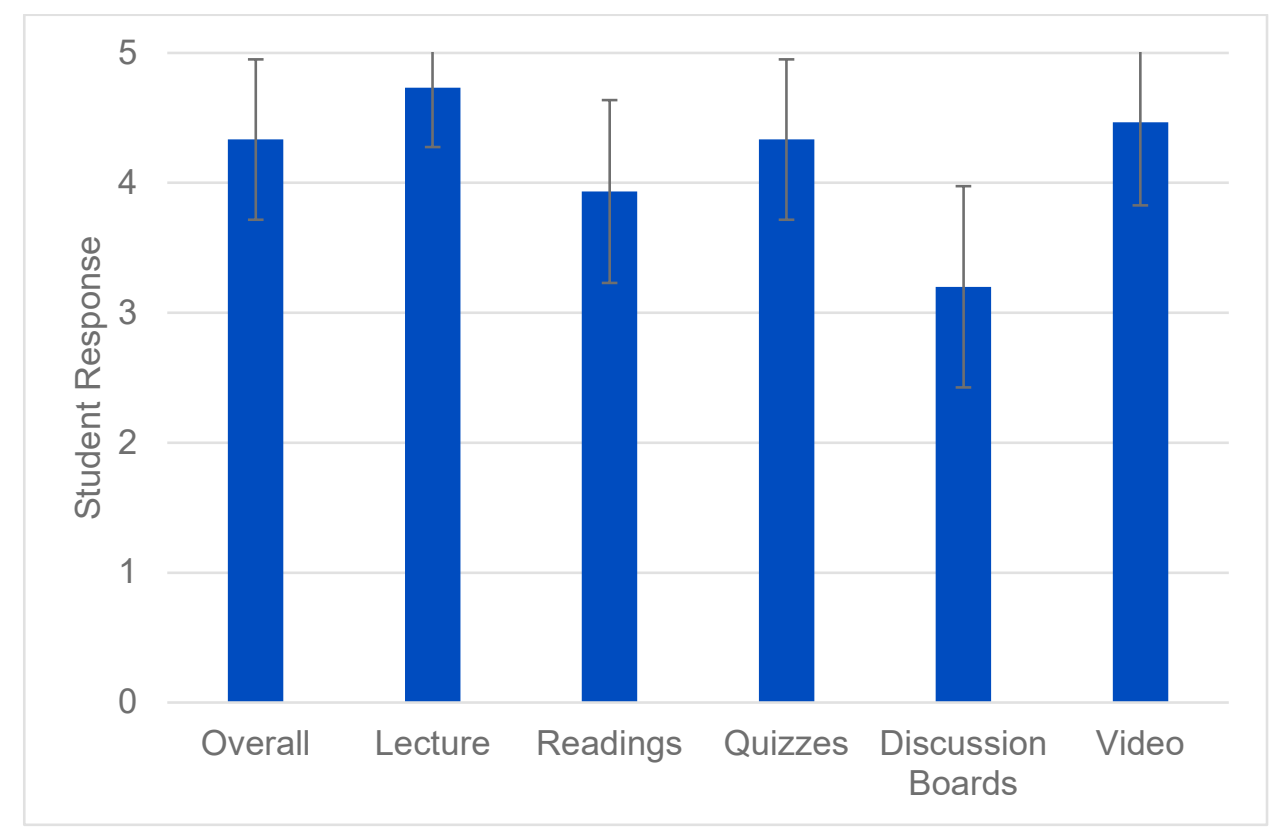

Figure 9. Student response to perception of usefulness of various elements of a lecture-based course.

Students were surveyed to evaluate their perceptions of their ability to handle the online/remote classes. The results are shown in Figure 10. It can be seen that their feelings are distributed across the spectrum of responses.

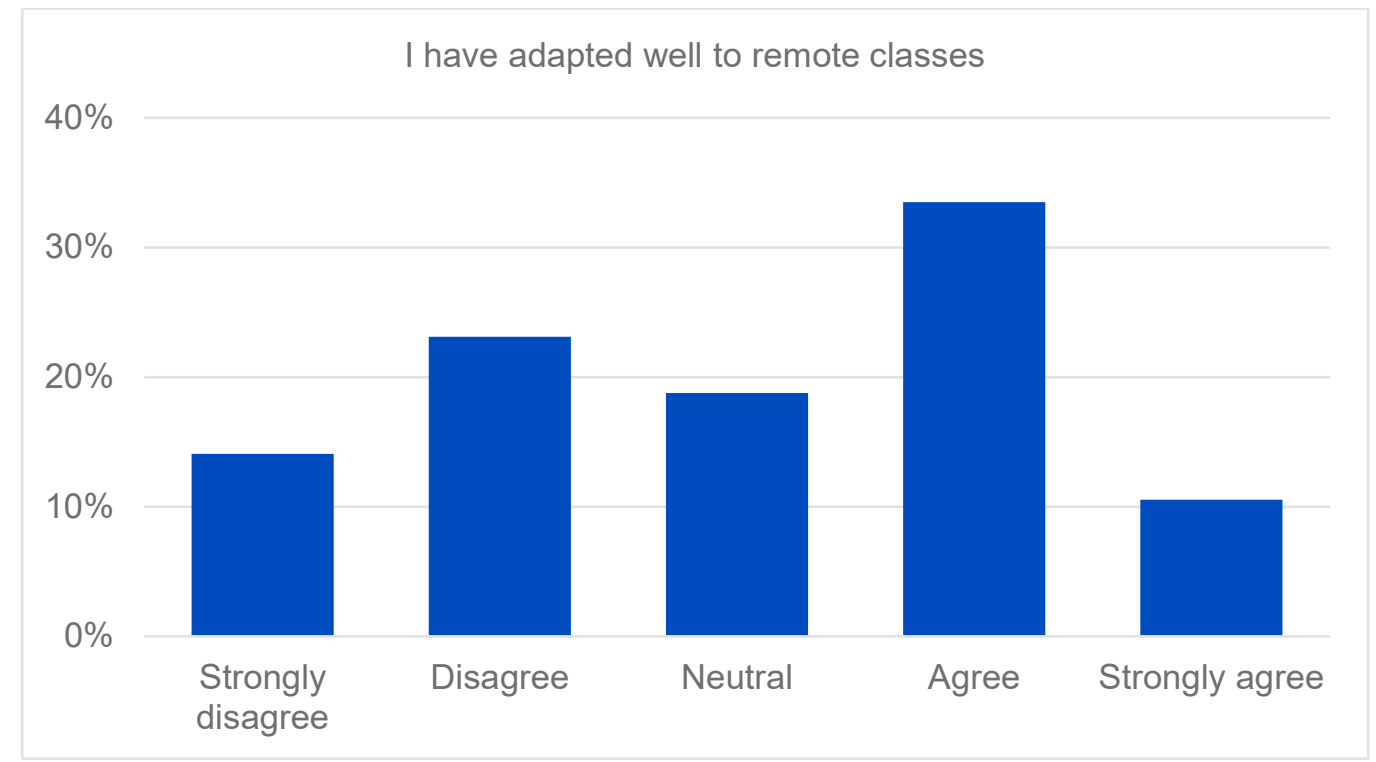

Figure 101. Students' self-assessment of their ability to adapt to remote classes. Approximately 600 students participated in this survey.

Students were also asked to evaluate how well their instructors have dealt with the transition. The results are shown in Figure 11. It can be seen that the students had a generally favorable impression of the faculty's ability to adapt to the situation. 


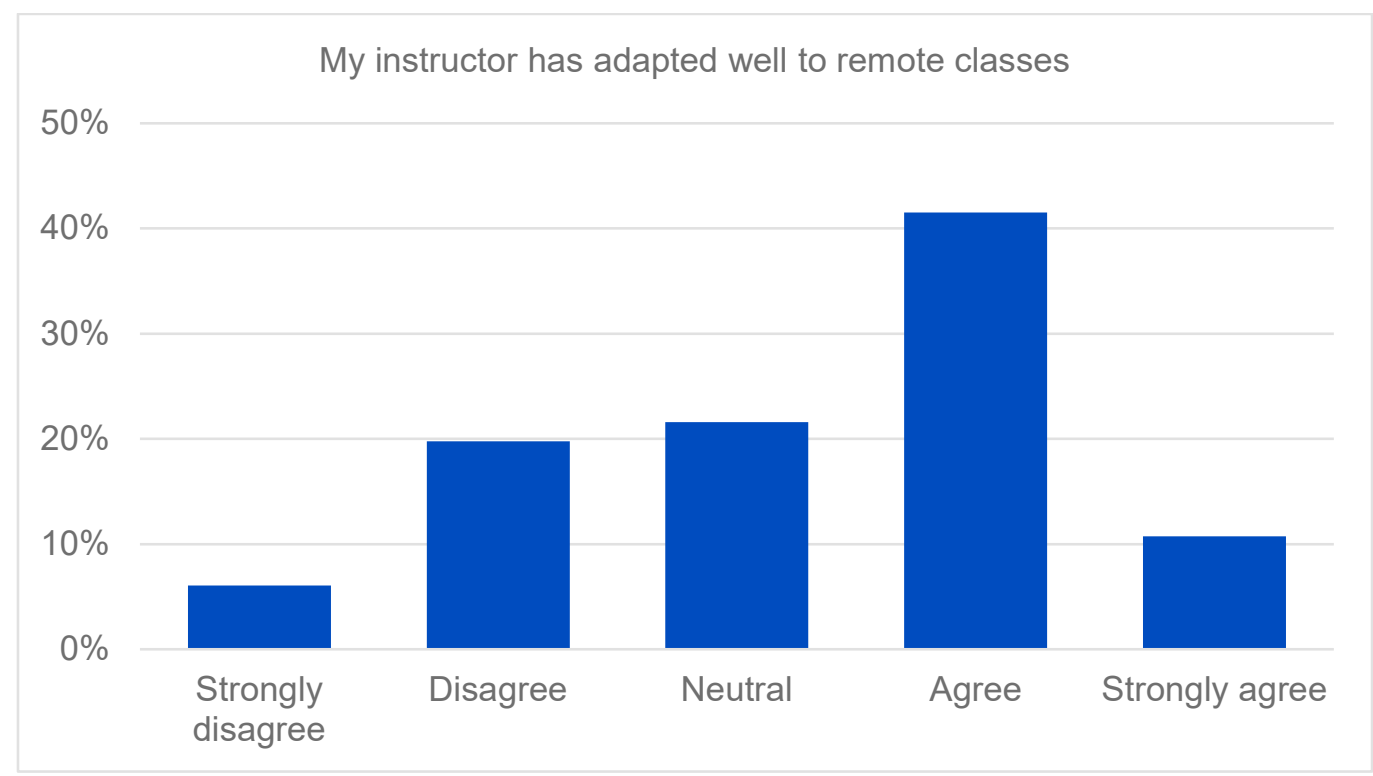

Figure 11. Students' perceptions of their instructors' ability to adapt to the remote teaching environment. Approximately 600 students participated in this survey.

Focusing on the students who expressed difficulties with adapting, their comments fell into seven main themes:

1. Lack of flexibility from professors as well as increased workload

2. Need improved online delivery (format, programs, content) vs "busy work"

3. Technology \& internet issues at home

4. Difficulty concentrating off campus (distractions) and adapting to online format

5. Financial stress/unemployment/working multiple jobs

6. Caring for family while at home \& family issues

7. Mental health issues/anxiety

These students offered recommendations to improve the experience:

- Partial tuition reimbursement

- Refund for services no longer provided (i.e. gym, library, housing)

- Provide further hands-on skills labs for soon to be graduate nurses

- Professors need to work on making content and lectures more concise

- Improve quality of course material delivered online

- Decrease workload and provide leniency - many professors are unaccommodating

- Improve communication from faculty to students

\section{Faculty Response}

The faculty response to the sudden switch to remote teaching was varied. For many faculty, the timing, restrictions regarding access to teaching spaces and limited resources created a significant challenge.

Conversely, the transition required a switch to digital assignment submissions which created a greater ease of content collection for program assessment.

The administrations in Germany and US developed robust faculty development programs, including "how to" videos, as well as online training sessions and workshops. Software licenses were provided to faculty for various digital tools. 
In April, 2020, faculty in the US were asked in a survey to evaluate their level of confidence with online teaching. As can be seen in Figure 12, faculty expressed a fairly high level of confidence in their ability to teach online, which is consistent with student perceptions, although slightly more optimistic.

\section{How confident are you with teaching online}

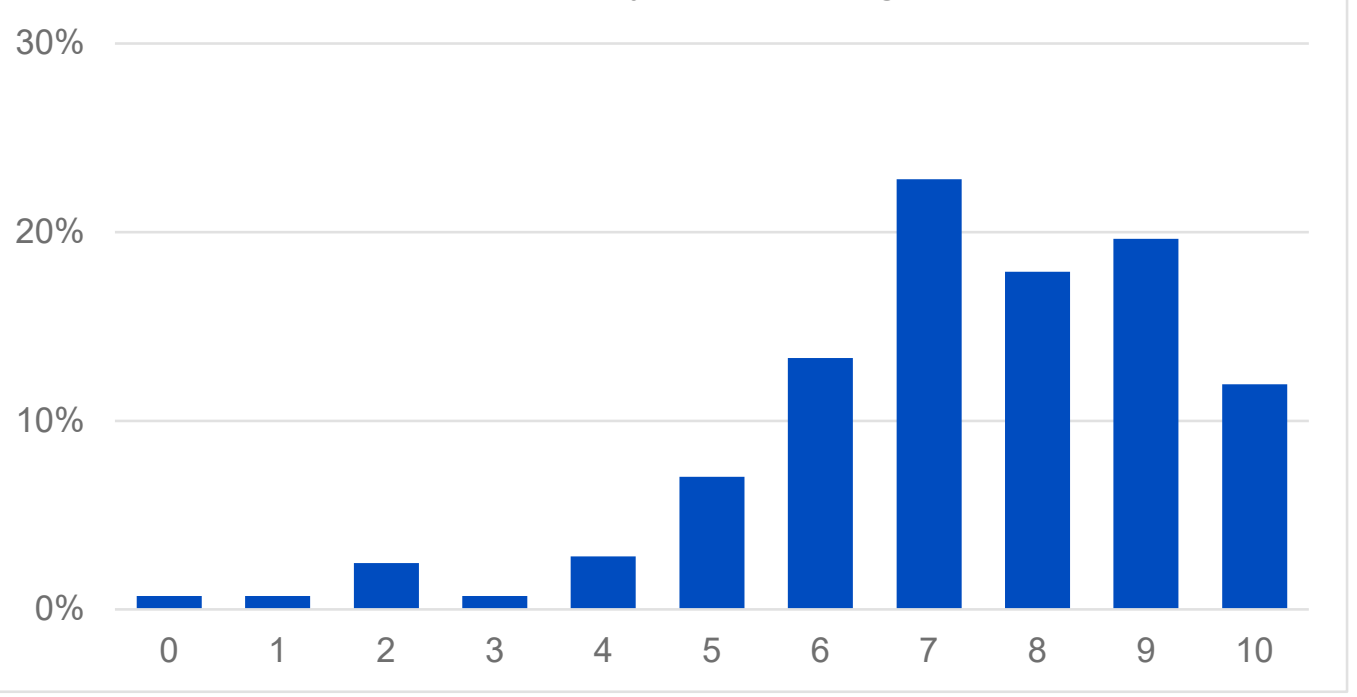

Figure 12. Faculty survey response to the question "How confident are you with teaching online." Response ranged from 0 (no confidence at all) to 10 (completely confident). Approximately 300 faculty members responded to the survey.

\section{Discussion and Concerns}

The challenges facing all of us are similar, but to different degrees. Students with no internet access (or poor-quality access) are a concern, although more common in SA than in the other countries. Even in the US, where it is mandatory for a student to own a computer while attending TJU, there are occasions where the device has failed, or a student could not afford one. In the past we would have directed such students to the public library, but those are closed.

This mode of learning has presented various challenges and required faculty to do significant work before the semester began. These dedicated instructors learned to use video-recording equipment and video-editing software on their own time to generate these teaching tools.

Learning environments are social communities. The studio/lab experience for members of the TJU textile student group solidifies the cohort's bonds and develops the open channels of communication. This genuine communication impacts critiques and feedback opportunities as well as the sharing of knowledge and peer-mentorship. Those relationships are developed during hours working and supporting one another in the communal studio/lab environment. The concern exists that the loss of that open studio freedom might result in a shift in the studio culture. Faculty are working to develop online opportunities for students to interact and bond. So far, student buy-in to these experiences has been positive, but the future will show how the blended/hybrid learning experiences affect student interactions and peer-support.

Generally, faculty felt that the transition was a heavy lift, requiring effort beyond their normal workload. At the writing of this paper, the US is in their 3rd semester of online teaching, and the faculty have adapted and have fewer complaints about the excess burden.

Several faculty have indicated that there will be positive outcomes from this experience, as they have learned to use more digital tools that will be helpful even in the "normal" classroom environment. 
In the knitting classes, the instructional videos that were developed to explain the operation of the machinery to students was very successful. Students came to the lab in small groups and the instructor observed that they were able use the equipment more effectively and with greater success than previous classes. Additionally, as they were knitting they were able to refer back to those videos and zoom in to see specific elements in detail.

For labs that could not meet in person, small kits were assembled and sent to each student's home so they could perform experiments remotely. Instructors provided introductory videos and the labs were performed online synchronously. The instructor indicated that this was effective and students expressed a positive experience including student opinions that there was less pressure when they were working at home than when surrounded by classmates.

For large equipment, such as ultrasonic seaming, there was no solution for at-home explorations. It was necessary for the students to come to the university in person, but in small groups, to operate it. But for smaller equipment, some home sewing machines were purchased and sent around from student to student to experiment and develop practical skills at home. A rotating set of small equipment can be developed with students working on projects in a cyclical manner.

\section{References}

[1] Francie Diep and Andy Thomason. UNC Pulls the Plug on In-Person Fall. Will Other Campuses Follow? (August 18, 2020) Available from: https://www.chronicle.com/article/unc-pulls-the-plug-on-in-person-fall-will-othercampuses-follow

[2] University of Notre Dame. Notre Dame Covid-19 Dashboard. Available from: https://here.nd.edu/ourapproach/dashboard/

[3] Randy Woodson. Fall Semester Undergraduate Classes Moving Online. (August 20, 2020) Available from: https://www.ncsu.edu/coronavirus/fall-semester-undergraduate-classes-moving-online/

[4] M. A. da Silveira and L. C. Scavarda-do-Como. 1999. Sequential and concurrent teaching: structuring hands-on methodology. IEEE Trans Educ. 42, 2, 103-108.

[5] Brian Beatty. 2014. Hybrid courses with flexible participation: The HyFlex course design. In: Lydia Kyei-

Blankson, Esther Ntuli (Eds.). Practical Applications and Experiences in K-20 Blended Learning Environments. IGI Global, Pennsylvania, USA, pp. 153-177.

[6] N. Solihati, H. Mulyono. 2017. A hybrid classroom instruction in second language teacher education (SLTE): A critical reflection of teacher educators. Int. J. Emerg. Technol. Learn. 12, 5,169-180.

[7] B. Manamela. (August 26, 2020). Coronavirus COVID-19 Alert Level 2 Measures in the Post School Education and Training Sector. Retrieved June 15, 2020 from: https://www.gov.za/speeches/minister-blade-nzimandecoronavirus-covid-19-alert-level-2-measures-post-school-education.

[8] J. A. Klemens, C. Pastore, M. Hudson. 2015. Harness student creativity and expertise. In: C. Sweet, H. Blythe, R. Carpenter (Eds.). It works for me, flipping the classroom. New Forum Press, Stillwater, OK.

[9] OPAL. Available from: https://bildungsportal.sachsen.de/portal/

[10] DFN Conference. Available from: https://www.conf.dfn.de/

[11] DokuWiki. Available from: www.dokuwiki.org

[12] Laura Czerniewicz. (March 15, 2020). What we learnt from "going online" during university shutdowns in South Africa. PhilOnEdTech. Available from: https://philonedtech.com/what-we-learnt-from-going-online-during-universityshutdowns-in-south-africa/

[13] Robert M. Bernard, Philip C. Abrami, Eugene Borokhovski, C. Anne Wade, Rana M. Tamim, Michael A. Surkes, Edward Clement Bethel. 2009. A meta-analysis of three types of interaction treatments in distance education. Review of Educational Research 79, 3, 1243-1289.

[14] Barbara Means, Marianne Bakia, Robert Murphy. 2014. Learning online: what research tells us about whether, when and how (1st ed.). Routledge, London, England.

[15] John A. Milligan. 2020. What is the value of synchronous engagement in small remote organic chemistry classes? Analysis of multiple-choice polling data from the COVID-impacted spring semester of 2020. J. Chem. Educ. 97, 9, 3206-3210.

[16] C. J. Bonk, C. Graham (Eds.). 2006. The handbook of blended learning: global perspectives, local designs (1st ed.) Pfeiffer, San Francisco, USA.

[17] Lydia Kyei-Blankson, Francis Godwyll, Mohamed A. Nur-Awaleh. 2014. Innovative blended delivery and learning: exploring student choice, experience, and level of satisfaction in a hyflex course. International Journal of Innovation and Learning 16, 3, 243-252. 
[18] D. Michele Jacobsen, Rob Kremer, Mildred L. G. Shaw, Niek J. E. Wijngaards. 1999. The learning web: a technical evaluation of webCT in concurrent classroom and distance education sections of a software engineering graduate course. In B. Collis, R. Oliver (Eds.). Proc. of EdMedia 1999 - World Conference on Educational Multimedia, Hypermedia \& Telecommunications. Seattle, WA, USA: Association for the Advancement of Computing in Education, 1340-1341.

[19] Clyde Freeman Herreid and Nancy A. Schiller. 2013. Case studies and the flipped classroom. Journal of College Science Teaching 42, 5, 62-66.

[20] Yanjie Song and Manu Kapur. 2017. How to flip the classroom - "Productive Failure or traditional flipped classroom" pedagogical design? Educational Technology \& Society 20, 1, 292-305.

[21] Adekunle Oladipupo Bamiro. 2015. Effects of Guided Discovery and Think-Pair-Share Strategies on Secondary School Students' Achievement in Chemistry. SAGE Open 5, 1, 2158244014564754.

[22] Nicky Hockly. 2018. Blended Learning. ELT Journal 72, 1, 97-101. 